\title{
Brazilian physicians' practices on the management of symptoms suggesting gastroesophageal reflux disease: a multidisciplinary survey
}

\author{
Decio CHINZON ${ }^{1}$, Joaquim Prado P MORAES-FILHO'1, Gerson DOMINGUES ${ }^{2}$, \\ Fabiana ROVEDA ${ }^{3}$, Abner Augusto LOBÃO NETO ${ }^{3}$ and Schlioma ZATERKA ${ }^{1}$
}

Received: 2 April 2020

Accepted: 21 July 2020

\begin{abstract}
Background - Clinical guidelines are available to steer decisions regarding diagnosis, management and treatment of gastrointestinal disorders. Despite this, variations in physician's practices regarding gastroesophageal reflux disease (GERD) symptoms are well described in the literature. Objective - To describe practices of physicians from different specialties on the management of patients with typical symptoms of GERD (heartburn and regurgitation) in a Brazilian sample. Methods - National online survey enrolling a sample of general practitioners, gastroenterologists, cardiologists and otolaryngologists. The survey was conducted from August 6th to September 12th, 2018. Subjects answered a structured questionnaire addressing variables regarding physicians' profile (age, sex, specialty, practice setting, years in practice, type of medical expense reimbursement), their patients characteristics and prescribing behaviors. Results - The final weighted sample was comprised of 400 physicians, $64 \%$ male, with an average of 15 years of experience. Physicians' estimates of gastroesophageal symptoms prevalence among their pool of patients was $37.6 \%$ for the total sample, reaching $70.3 \%$ among gastroenterologists. The medical specialty with lower average percentage of patients presenting gastroesophageal symptoms was otolaryngology $(24.5 \%)$. Physicians reported that they request ancillary tests for $64.5 \%$ of patients with GERD typical symptoms. The most common diagnostic test was endoscopy $(69.4 \%)$, followed by video nasolaryngoscopy $(16.6 \%)$. The percentage of patient to whom endoscopy is performed was significantly higher among gastroenterologists and general practitioners as compared to otolaryngologists and cardiologists, while video nasolaryngoscopy is markedly more frequent among otolaryngologists. In terms of therapeutic options, the most frequently reported strategy was lifestyle modifications followed by proton pump inhibitors. Conclusion - Overall patients' profile and patterns of GERD diagnosis and management seem different between gastroenterologists, general practitioners, otolaryngologists, and cardiologists. Clinical guidelines should address this variability and include other medical specialties besides gastroenterologists in their scope.
\end{abstract}

HEADINGS - Gastroesophageal reflux. Pathological conditions, signs and symptoms. Professional practice, standards. Surveys and questionnaires.

\section{INTRODUCTION}

Gastroesophageal reflux disease (GERD) figures among the most prevalent gastrointestinal diagnosis worldwide, resulting in significant impairment in patients' quality of life ${ }^{(1-3)}$. In 2010 in the USA, GERD led to over 7 million visits to care providers in outpatient facilities and emergency units ${ }^{(3)}$. The condition is defined as a retrograde flow of gastric contents to the esophagus, resulting in symptoms and/or complications s $^{(4,5)}$. A meta-analysis addressing GERD epidemiology identified 108 studies reporting prevalence data ranging from $2.5-51.2 \%$, depending on the study and country ${ }^{(6)}$. In Brazil, prevalence estimates range from $7.3 \%^{(7)}$ to $20 \% \%^{(8,9)}$, depending on GERD definition and study design.

Previous studies have investigated differences in terms of diagnostic approaches and prescribing behaviors among physicians from different specialties and also in terms of greater or lesser experience $^{(10-13)}$. Bretagne et al. ${ }^{(10)}$ compared usual medical practices for the diagnostic and therapeutic management of GERD symptoms between primary care physicians and gastroenterologists. The authors identified that upper endoscopy was more frequently prescribed by gastroenterologists than primary care physicians and also observed slightly different patterns of drug prescription, even though lifestyle modifications were common in both groups. Halpern et al. ${ }^{(1)}$ also proposed a similar comparison between primary care doctors and gastroenterologists and identified a significantly increased resource utilization among patients treated by specialists (such as more outpatient visits, endoscopies, surgeries and invasive procedures).

Most published studies focused only in primary care physicians and/or general practitioners, but did not include other medical specialties. Thus, the present study aimed to describe physicians' practices on the management of patients with typical symptoms of GERD (heartburn and regurgitation) among Brazilian gastroenterologists, general practitioners (GP), otolaryngologists, and cardiologists.

Declared conflict of interest of all authors: Chinzon D has received fees as advisory board member for Takeda and Hypera. Moraes-Filho JPP has received fees as speaker for Takeda. Domingues $\mathrm{G}$ has received fees as speaker for Takeda and Hypera. Roveda F was a medical manager at Takeda when the manuscript was written. Lobão Neto AA is currently a medical director at Takeda. Zaterka $S$ has received fees as advisory board member for Takeda and Ache; speaker for EMS and Takeda.

Disclosure of funding: the study was supported by Takeda Pharmaceuticals Brazil.

${ }^{1}$ Universidade de São Paulo, Faculdade de Medicina, São Paulo, SP, Brasil. ${ }^{2}$ Universidade Estadual do Rio de Janeiro, Faculdade de Medicina, Rio de Janeiro, RJ, Brasil. ${ }^{3}$ Takeda Pharmaceuticals - Brazil.

Corresponding author: Decio Chinzon. E-mail: clinica.chinzon@uol.com.br 


\section{METHODS}

This was a national online survey that aimed to describe physicians' practices about the management of symptoms associated with GERD. The survey was conducted from August 6th to September 12th, 2018. To recruit a representative sample of Brazilian physicians, quotas for region of the country were applied to an already existing nationwide probability-based web panel of physicians who participate in opinion surveys. The sample was weighted by the distribution of each specialty of interest (cardiology, gastroenterology, otolaryngology, and primary care) in the country according to the 2018 Brazilian Medical Census ${ }^{(14)}$ as well as by the geographic distribution of each medical specialty according to Brazilian macro-regions. Weighting was performed using the Rim Weighting approach, commonly adopted in opinion surveys to adjust to multiple characteristics simultaneously. The method is based on iterations adjusted to fit the population proportions of the selected weighting factors. The weighting is employed to correct potential misbalances in the sample in terms of the two original quota targets (medical specialty and region).

After receiving information about study procedures and agreeing in participating, subjects were presented with questions about demographics, practice setting, and experience. To explore physicians' practices and perceptions, the subsequent questions addressed frequency and severity of gastrointestinal symptoms among patients, routine usage of ancillary tests to establish a diagnosis, and prescribing behaviors. Severity of gastrointestinal symptoms was addressed using three mutually exclusive categories: mild, moderate, and severe. Physicians were asked to classify symptoms according to their own criteria.

All statistical analyses were performed in SPSS (IBM SPSS Statistics for Windows Released 2015, Version 23.0. Armonk, NY: IBM Corp.) and a two-tailed p-value of less than .05 was considered statistically significant. In bivariate analyses, categorical variables were compared using independent $Z$-test and continuous variables were explored using independent $t$-test, when applicable.

This study was based on results of an opinion survey and, thus, no approval was required from the Research Ethics Committee. Likewise, it was not necessary to sign an Informed Consent Form. However, all procedures performed are governed by ethical standards of the Brazilian Association of Research Companies (ABEP) and of the European Society of Market Research (ESOMAR), in compliance with the International Standard for Quality on Market and Opinion Research - ISO 20252:2006 and the International Standard for Quality Management ISO 9001:2000.

\section{RESULTS}

The final weighted sample was comprised of 400 physicians, $64 \%$ male, with an average of 15 years of experience. The most represented medical specialty in the sample was general practitioners (61.5\%). Socio-demographic sample characteristics are presented in TABLE 1.

TABLE 2 presents our findings about patients' characteristics as reported by surveyed physicians. They attend an average of 362 patients/month, most commonly covered by private health insurance plans $(58.7 \%)$. Physicians' estimates of typical gastroesophageal reflux symptoms prevalence among their usual pool of patients was $37.6 \%$ for the total sample, reaching $70.3 \%$ among gastroenterologists. The medical specialty with lower average per-
TABLE 1. Physicians' characteristics $(n=400)$.

\begin{tabular}{|c|c|c|c|}
\hline Characteristic & & $\mathbf{N}$ & $\%$ \\
\hline \multicolumn{4}{|l|}{ Sex } \\
\hline & Female & 144 & 36.0 \\
\hline & Male & 256 & 64.0 \\
\hline \multicolumn{4}{|c|}{ Medical specialty } \\
\hline & Gastroenterologist & 28 & 7.0 \\
\hline & General Practitioner & 246 & 61.5 \\
\hline & Otolaryngologist & 37 & 9.3 \\
\hline & Cardiologist & 89 & 22.2 \\
\hline \multicolumn{4}{|c|}{ Years of experience } \\
\hline & $3-10$ years & 152 & 38.0 \\
\hline & $11-20$ years & 170 & 42.7 \\
\hline & $21-30$ years & 55 & 13.7 \\
\hline & $>30$ years & 23 & 5.6 \\
\hline & Mean [years] & & \\
\hline \multicolumn{4}{|c|}{ Geographic region } \\
\hline & North & 11 & 2.7 \\
\hline & Northeast & 71 & 17.8 \\
\hline & Midwest & 38 & 9.6 \\
\hline & Southeast & 210 & 52.5 \\
\hline & South & 70 & 17.5 \\
\hline
\end{tabular}

TABLE 2. Patients' characteristics as reported by surveyed physicians.

\begin{tabular}{lc}
\hline Characteristics & Mean \% \\
\hline Number of patients per month [mean number] & 362 \\
Type of financing of healthcare services* & \\
Health insurance/private healthcare plans & 58.7 \\
Public/governmental & 23.3 \\
Out-of-pocket (patient or family direct payment) & 18.0 \\
Prevalence of GERD symptoms among attended patients* & \\
Gastroenterologist & 70.3 \\
General Practitioners & 38.6 \\
Otolaryngologist & 24.5 \\
Cardiologist & 30.2 \\
Total sample & 37.6 \\
Distribution of gastroesophageal symptoms severity level* & \\
Mild & 52.9 \\
Moderate & 33.1 \\
Severe & 14.0 \\
\hline
\end{tabular}

*Answers refer to mean percentage referred by doctors when asked about the proportion of their usual pool of patients that usually present each examined variable; $\dagger$ statistically significant difference between $=$ all specialties $(P<0.05)$

centage of patients presenting gastroesophageal symptoms was otolaryngology $(24.5 \%)$. More than half of symptomatic patients present mild symptoms, according to physicians' opinion $(52.9 \%)$.

Subjects reported that they request ancillary tests (such as endoscopy with or without a biopsy, video nasolaryngoscopy, conventional or impedance $\mathrm{pH}$-metry, and esophageal manometry) for $64.5 \%$ of patients (TABLE 3). Differences in this frequency 
TABLE 3. Prescription profile - ancillary tests.

\begin{tabular}{lc}
\hline Characteristics & Mean $\%$ \\
\hline $\begin{array}{l}\text { Percentage of symptomatic patients to whom ancillary } \\
\text { tests are requested* }\end{array}$ & 64.5 \\
By medical specialty* ${ }^{\dagger}$ & \\
Gastroenterologist & 74.4 \\
General practitioner & 60.5 \\
Otolaryngologist & 80.9 \\
Cardiologist & 65.2 \\
By years of experience* & \\
3-10 years & 60.0 \\
$11-20$ years & 65.3 \\
$21-30$ years & 71.8 \\
$>30$ years & 71.5
\end{tabular}

Percentage of symptomatic patients to whom each specific test is requested*

Endoscopy (with or without abiopsy)

Video nasolaryngoscopy

Conventional or impedance $\mathrm{pH}$-metry

Esophageal manometry

Endoscopy frequency by medical specialty*

Gastroenterologist

General practitioner

Otolaryngologist ${ }^{\S}$

Cardiologist ${ }^{\S}$

Video nasolaryngoscopy frequency by medical specialty*

Gastroenterologist

General practitioner"

Otolaryngologist ${ }^{\S}$

Cardiologist

pH-metry frequency by medical specialty*

$$
\text { Gastroenterologist }{ }^{\text {III }}
$$

General practitioner ${ }^{\mathrm{iii}}$

Otolaryngologist

Cardiologist

Esophageal manometry frequency by medical specialty*

Gastroenterologist ${ }^{\S}$

General practitioner ${ }^{\mathrm{iii}}$

Otolaryngologist

*Answers refer to mean percentage referred by physicianswhen asked about the proportion of their usual pool of patients that usually present each examined variable; $†$ statistically significant difference between all subgroups $(P<0.05)$; $\ddagger$ statistically significant difference versus 21-30 years $(P<0.05)$; $\S$ statistically significant difference versus all other subgroups $(P<0.05)$; $\|$ statistically significant difference versus gastroenterologists and cardiologists $(P<0.05)$; III statistically significant differences versus otolaryngologists and cardiologists $(P<0.05)$. reached statistical significance $(P<0.05)$ when medical specialties were compared and subjects with 3-10 years of experience had a significantly lower frequency than those with $21-30$ years $(P<0.05)$. Among physicians who reported prescribing diagnostic tests for patients with GERD typical symptoms, the most frequently requested tests were endoscopy (with or without a biopsy), video nasolaryngoscopy, conventional or impedance $\mathrm{pH}$-metry, and esophageal manometry (TABLE 3 ). The most common diagnostic subsidiary test was endoscopy $(69.4 \%)$, followed by video nasolaryngoscopy $(16.6 \%)$. Statistically significant differences $(P<0.05)$ were observed according to medical specialty in terms of the mean percentage of patients to whom each specific test is requested (TABLE 3). The percentage of patients submitted to endoscopy is significantly higher among gastroenterologists and general practitioners as compared to otolaryngologists and cardiologists, while video nasolaryngoscopy is markedly more frequent among otolaryngologists.

In terms of therapeutic options, the most frequently reported strategy was lifestyle modifications followed by proton pump inhibitors (PPI), regardless of severity of complaints (TABLE 4). Medical specialty was not associated with differences in treatment prescription in the sample $(P>0.05$ for all comparisons and therapeutic options).

TABLE 4. Prescription profile - treatment for patients with a GERD diagnosis.

\begin{tabular}{lccc}
\hline \multirow{2}{*}{ Therapeutic option } & Mild & Moderate & Severe \\
\cline { 2 - 4 } & \multicolumn{3}{c}{ Mean \% } \\
\hline Lifestyle changes & 95.0 & 91.0 & 87.0 \\
Proton pump inhibitors & 79.0 & 75.0 & 80.0 \\
Antacids & 68.0 & 57.0 & 54.0 \\
H2 receptor antagonists & 59.0 & 47.0 & 47.0 \\
Surgery & 34.0 & 28.0 & 42.0 \\
Natural remedies/herbal therapy & 30.0 & 22.0 & 22.0 \\
Prokinetic agents & 13.0 & 11.0 & 13.0 \\
\hline
\end{tabular}

\section{DISCUSSION}

The present study enrolled a representative sample of Brazilian physicians across the country from medical specialties that usually attend patients with GERD typical symptoms. As expected, gastroenterologists reported higher frequencies, but the average reported frequency was approximately $25 \%$ of all patients even among otolaryngologists. Almost half of the patients had moderate to severe symptoms, as reported by enrolled physicians.

It was reported that for $64.5 \%$ of patients with GERD typical symptoms, ancillary tests are prescribed. Otolaryngologists and gastroenterologists request diagnostic tests with statistically significant higher frequency than GPs and cardiologists. Similar trends for gastroenterologists and GPs were previously described by Lacy et al. and Halpern et al. for the US and Bretagne et al. for France ${ }^{(10,11,13)}$. Wong et al. ${ }^{(15)}$ also enrolled otolaryngologists in their study in Asia-Pacific region and observed that otolaryngologists and gastroenterologists presented a similar frequency of "testing before treating" approach (approximately 30\%), higher than the one observed for primary care physicians in their sample $(13 \%)$. Despite different methods and variable definitions, the present findings indicate a higher frequency of diagnostic tests 
to establish a GERD diagnosis among otolaryngologists and gastroenterologists than other medical specialties, consistent with Wong et al. observation ${ }^{(15)}$.

The most frequently reported diagnostic methods by physicians in our sample were endoscopy, followed by video nasolaryngoscopy, and $\mathrm{pH}$-metry. With the exception of video nasolaryngoscopy (that was predominantly reported by otolaryngologists), the same tests were mentioned in Bretagne et al. (France) and Wong et al. (AsiaPacific region), as well as in the Brazilian GERD Guidelines ${ }^{(4,16)}$, indicating that our respondents practices seems to be aligned with international settings and also local clinical guidelines. The use of an empiric trial with PPIs was not assessed in our survey, limiting our ability to adequately address practices concerning "therapeutic tests" or the "treating before testing" approach in Brazil.

Regarding GERD treatment options, the most frequently mentioned therapeutic strategies were lifestyle modifications and PPIs, with a smaller space for antacids, $\mathrm{H} 2$ antagonists and other drugs. A systematic review published by Ness-Jensen et al. ${ }^{(17)}$ included 15 individual studies, two systematic reviews ${ }^{(18,19)}$ and also three guidelines (Canadian Association of Gastroenterology; American Gastroenterological Association; and American College of Gastroenterology) addressing the effectiveness of lifestyle modifications in the management of GERD symptoms. The authors identified that lifestyle changes like weight loss, markedly decreased the time with acid exposure ${ }^{(17)}$. Likewise, the efficacy and safety of PPIs to treat patients with GERD symptoms is well-established in the literature, as supported by meta-analysis conducted by Chen et al. ${ }^{(20)}$ and $\mathrm{Li}$ et al. ${ }^{(21)}$, justifying the recommendation of PPIs as first choice for these patients as stated in international guidelines ${ }^{(22-25)}$. These data reinforce that current prescription behaviors of Brazilian physicians in our sample are also in line with available evidence, as observed for diagnostic strategies.

The main limitation of the present study is related to the data source, since patient-level data about outcome variables were not available. Another limitation may be represented by the proportion of physicians practicing in public versus private settings, which differs from the national distribution of patients assessing health care with each financing source (approximately $76 \%$ of the Brazilian population does not have access to private health insurance). Comparability of present findings with previous studies with similar aims is limited due to the adoption of different designs, methods, and sample characteristics. In terms of between-subgroup comparisons, the small sample size in each subgroup also limited the statistical power of some analysis, mainly in terms of prescribing behaviors between investigated medical specialties. Despite these limitations, the present survey enrolled a representative sample of physicians with different backgrounds, providing a comprehensive overview of practices of Brazilian doctors towards GERD symptomatic patients. Future analysis using patient-level data about GERD diagnosis and treatment patterns may offer a more in-depth view of the topic.

\section{CONCLUSION}

Overall patients' profile and patterns of GERD diagnosis seem different between gastroenterologists, general practitioners, otolaryngologists, and cardiologists in the present sample. This observation is particularly relevant for the proportion of sympto- matic patients for whom diagnostic tests are requested to establish a diagnosis and also for the type of tests usually prescribed. Clinical guidelines should address this variability and include other medical specialties besides gastroenterologists in their scope.

\section{ACKNOWLEDGEMENTS}

The authors thank Maíra Takemoto of ANOVA Health Consulting Group for providing medical writing support and editorial support, which was funded by Takeda Pharmaceuticals, São Paulo, Brazil in accordance with Good Publication Practice (GPP3) guidelines.

\section{Authors' contribution}

Chinzon D: acquisition, analysis, or interpretation of data for the work; revising it critically for important intellectual content; final approval of the version to be published; agreement to be accountable for all aspects of the work in ensuring that questions related to the accuracy or integrity of any part of the work are appropriately investigated and resolved.

Moraes-Filho JPP: acquisition, analysis, or interpretation of data for the work; revising it critically for important intellectual content; final approval of the version to be published; agreement to be accountable for all aspects of the work in ensuring that questions related to the accuracy or integrity of any part of the work are appropriately investigated and resolved.

Domingues $\mathrm{G}$ acquisition, analysis, or interpretation of data for the work; revising it critically for important intellectual content; final approval of the version to be published; agreement to be accountable for all aspects of the work in ensuring that questions related to the accuracy or integrity of any part of the work are appropriately investigated and resolved.

Roveda F: acquisition, analysis, or interpretation of data for the work; revising it critically for important intellectual content; final approval of the version to be published; agreement to be accountable for all aspects of the work in ensuring that questions related to the accuracy or integrity of any part of the work are appropriately investigated and resolved.

Lobão Neto AA: acquisition, analysis, or interpretation of data for the work; revising it critically for important intellectual content; final approval of the version to be published; agreement to be accountable for all aspects of the work in ensuring that questions related to the accuracy or integrity of any part of the work are appropriately investigated and resolved.

Zaterka S: acquisition, analysis, or interpretation of data for the work; revising it critically for important intellectual content; final approval of the version to be published; agreement to be accountable for all aspects of the work in ensuring that questions related to the accuracy or integrity of any part of the work are appropriately investigated and resolved.

\section{Orcid}

Chinzon D: 0000-0003-3030-6687.

Moraes-Filho JPP: 0000-0003-1280-6047.

Domingues G: 0000-0003-0431-451X.

Roveda F: 0000-0003-2898-717X.

Lobão A: 0000-0003-2969-6796.

Zaterka S: 0000-0002-2260-9146. 
Chinzon D, Moraes-Filho JPP, Domingues G, Roveda F, Lobão Neto AA, Zaterka S. Práticas de médicos brasileiros no manejo de sintomas sugestivos de doença do refluxo gastroesofágico: uma avaliação multidisciplinar. Arq Gastroenterol. 2020;57(4):404-8.

RESUMO - Contexto - Diretrizes clínicas estão disponíveis para orientar decisões sobre diagnóstico, manejo e tratamento de desordens gastrointestinais. Apesar disso, variações nas práticas relacionadas aos sintomas de doença do refluxo gastroesofágico (DRGE) são observadas na literatura. Objetivo Descrever os conhecimentos e práticas relacionados ao manejo de pacientes com sintomas típicos de DRGE (pirose e regurgitação) em uma amostra brasileira de médicos de especialistas e não especialistas. Métodos - Inquérito nacional online investigando a conduta frente ao diagnóstico de DRGE em uma amostra de médicos generalistas, gastroenterologistas, cardiologistas e otorrinolaringologistas. O inquérito foi conduzido entre 6 de agosto e 12 de setembro de 2018. Os sujeitos responderam a um questionário estruturado avaliando variáveis relacionadas ao perfil dos médicos (idade, sexo, especialidade, contexto de prática, anos de experiência, tipo de reembolso de despesas médicas), características dos pacientes e comportamentos de prescrição. Resultados - A amostra final ponderada foi composta por 400 médicos, $64 \%$ homens, com um tempo médio de experiência de 15 anos. A estimativa dos médicos a respeito da prevalência de sintomas gastroesofágicos entre seus pacientes foi de $37,6 \%$ para a amostra total, alcançando $70,3 \%$ entre gastroenterologistas. A especialidade médica com menor percentual de pacientes apresentando sintomas gastroesofágicos foi otorrinolaringologia (24,5\%). Os médicos requisitaram exames complementares em 64,5\% dos pacientes com sintomas típicos de DRGE. O exame diagnóstico mais frequente foi endoscopia $(69,4 \%)$, seguida de nasolaringoscopia $(16,6 \%)$. O percentual de pacientes nos quais uma endoscopia é realizada é significativamente maior entre gastroenterologistas e médicos generalistas, quando comparado a otorrinolaringologistas e cardiologistas, enquanto nasolaringoscopia é marcadamente mais frequente entre otorrinolaringologistas. Em termos de opções terapêuticas, a estratégia mais frequentemente reportada foi modificações no estilo de vida, seguida de inibidores da bomba de prótons. Conclusão - De modo geral, o perfil de pacientes e os padrões de diagnóstico e manejo de DRGE parecem diferir entre gastroenterologistas, médicos generalistas, otorrinolaringologistas e cardiologistas. Diretrizes clínicas devem abordar esta variabilidade e incluir outras especialidades médicas além de gastroenterologistas em seu escopo.

DESCRITORES - Refluxo gastroesofágico. Condições patológicas, sinais e sintomas. Prática profissional, normas. Inquéritos e questionários.

\section{REFERENCES}

1. Bruley Des Varannes S, Marek L, Humeau B, Lecasble M, Colin R. Gastroesophageal reflux disease in primary care. Prevalence, epidemiology and quality of life of patients. Gastroenterol Clin Biol. 2006;30:364-70.

2. Eslick GD, Talley NJ. Gastroesophageal reflux disease (GERD): risk factors, and impact on quality of life-a population-based study. J Clin Gastroenterol. 2009;43:111-7.

3. Peery AF, Crockett SD, Barritt AS, Dellon ES, Eluri S, Gangarosa LM, et al. Burden of Gastrointestinal, Liver, and Pancreatic Diseases in the United States. Gastroenterology. 2015;149:1731-41.e3.

4. Federação Brasileira de Gastroenterologia, Sociedade Brasileira de Endoscopia Digestiva, Colégio Brasileiro de Cirurgia Digestiva, Sociedade Brasileira de Pneumologia e Tisiologia. Doença do Refluxo Gastroesofágico: Diagnóstico. Diretrizes Clínicas na Saúde Suplementar. 2011. 1-6 p.

5. Federação Brasileira de Gastroenterologia. Projeto Diretrizes - Refluxo Gastroesofágico: Diagnóstico e Tratamento. Rev AMRIGS. 2006;50:251-63.

6. Eusebi LH, Ratnakumaran R, Yuan Y, Solaymani-Dodaran M, Bazzoli F, Ford AC. Global prevalence of, and risk factors for, gastro-oesophageal reflux symptoms: a meta-analysis. Gut. 2018;67:430-40.

7. Moraes-Filho JPP, Chinzon D, Eisig JN, Hashimoto CL, Zaterka S. Prevalence of heartburn and gastroesophageal reflux disease in the urban Brazilian population. Arq Gastroenterol. 2005;42:122-7.

8. Pereira-Lima J, Blaya C, Rynkowski CB, Althaus-Júnior W, Frey BN, Prati C, et al. Prevalência da doença do refluxo gastroesofágico: estudo populacional em Porto Alegre, Rio Grande do Sul. GED Gastroenterol Endosc Dig. 2000;19:73-8.

9. do Rosário Dias de Oliveira Latorre M, Medeiros da Silva A, Chinzon D, Eisig JN, Dias-Bastos TRP. Epidemiology of upper gastrointestinal symptoms in Brazil (EpiGastro): a population-based study according to sex and age group. World J Gastroenterol. 2014;20:17388-98.

10. Bretagne JF, Honnorat C, Richard-Molard B, Soufflet C, Barthélemy P. Perceptions and practices on the management of gastro-oesophageal reflux disease: Results of a national survey comparing primary care physicians and gastroenterologists. Aliment Pharmacol Ther. 2007;25:823-33.

11. Halpern R, Kothari S, Fuldeore M, Zarotsky V, Porter V, Dabbous O, et al. GERD-Related Health Care Utilization, Therapy, and Reasons for Transfer of GERD Patients Between Primary Care Providers and Gastroenterologists in a US Managed Care Setting. Dig Dis Sci. 2010;55:328-37.

12. Reimer C, Bytzer P. Perceptions and Beliefs concerning Gastroesophageal Reflux Disease: Physicians and Patients Disagree. Digestion. 2007;76(3-4):229-34.
13. Lacy BE, Crowell MD, Riesett RP, Mitchell A. Age, specialty, and practice setting predict gastroesophageal reflux disease prescribing behavior. J Clin Gastroenterol. 2005;39:489-94.

14. Scheffer M. Demografia Médica no Brasil - 2018. Departamento de Medicina Preventiva da USP; Conselho Regional de Medicina do Estado de São Paulo; Conselho Federal de Medicina, editor. São Paulo; 2018 [Internet]. [cited 2019 May 20]. 286 p. Available from: https://portal.cfm.org.br/index.php?option=com_content\&view $=$ article \&id=27509:2018-03-21-19-29-36\&catid $=3$

15. Wong WM, Lim P, Wong BCY. Clinical practice pattern of gastroenterologists, primary care physicians, and otolaryngologists for the management of GERD in the Asia-Pacific region: The FAST survey. J Gastroenterol Hepatol. 2004;19(Suppl. 3):54-60.

16. Henry MACA. Diagnóstico e tratamento da doença do refluxo gastroesofágico. ABCD Arq Bras Cir Dig. 2014;27:210-5.

17. Ness-Jensen E, Hveem K, El-Serag H, Lagergren J. Lifestyle Intervention in Gastroesophageal Reflux Disease. Clin Gastroenterol Hepatol. 2016;14:175-82. e1-3.

18. Kaltenbach T, Crockett S, Gerson LB. Are Lifestyle Measures Effective in Patients With Gastroesophageal Reflux Disease? Arch Intern Med. 2006;166:965.

19. De Groot NL, Burgerhart JS, Van de Meeberg PC, De Vries DR, Smout AJPM, Siersema PD. Systematic review: the effects of conservative and surgical treatment for obesity on gastro-oesophageal reflux disease. Aliment Pharmacol Ther. 2009;30:1091-102.

20. Chen L, Chen Y, Li B. The efficacy and safety of proton-pump inhibitors in treating patients with non-erosive reflux disease: a network meta-analysis. Sci Rep. 2016;6:32126.

21. Li M-J, Li Q, Sun M, Liu L-Q. Comparative effectiveness and acceptability of the FDA-licensed proton pump inhibitors for erosive esophagitis: A PRISMA-compliant network meta-analysis. Medicine (Baltimore). 2017;96:e8120.

22. Hunt R, Chen M, Melo AC, Ford A, Lazebnik L, Lizarzabal M, et al. World Gastroenterology Organisation Global Guidelines: GERD Global Perspective on Gastroesophageal Reflux Disease. J Clin Gastroenterol. 2017;51:467-78.

23. Lichtenstein DR, Cash BD, Davila R, Baron TH, Adler DG, Anderson MA, et al. Role of endoscopy in the management of GERD. Gastrointest Endosc. 2007;66:219-24.

24. Katz PO, Gerson LB, Vela MF. Guidelines for the Diagnosis and Management of Gastroesophageal Reflux Disease. Am J Gastroenterol. 2013;108:308-28.

25. Shaheen NJ, Weinberg DS, Denberg TD, Chou R, Qaseem A, Shekelle P, et al. Upper Endoscopy for Gastroesophageal Reflux Disease: Best Practice Advice From the Clinical Guidelines Committee of the American College of Physicians. Ann Intern Med. 2012;157:808. 